\title{
Repensando o déficit sociológico da teoria crítica: de Honneth a Horkheimer*
}

\author{
Rethinking the sociological deficit of critical theory: from Honneth \\ to Horkheimer
}

\author{
Rúrion Melo \\ rurion@usp.br \\ (Universidade de São Paulo, São Paulo, Brasil)
}

\begin{abstract}
Resumo: Com a conhecida crítica do "déficit sociológico", Honneth apontou a incapacidade de Horkheimer de realizar o programa principal da teoria crítica, a saber, vincular filosofia social com uma análise da sociedade que também se baseasse em pesquisas sociais empíricas. Contudo, por ter se distanciado do paradigma da "luta" e desenvolvido uma teoria preocupada mais com a "reconstrução normativa" das instituições de nossa vida democrática, Honneth acabaria dando menos atenção à relação com a pesquisa social. Defendemos que os trabalhos de Horkheimer da década de 1930 poderiam indiretamente nos ajudar a resolver algumas dificuldades metodológicas concernentes a uma espécie de "novo déficit sociológico" que a teoria crítica estaria enfrentando hoje.
\end{abstract}

Palavras-chave: teoria crítica; pesquisa social; Horkheimer; Honneth; teoria do reconhecimento.

\begin{abstract}
With the well-known critique of "sociological deficit", Honneth pointed out Horkheimer's inability to carry out the main program of critical theory, namely, to link social philosophy with an analysis of society that was also based on empirical social research. However, because he distanced himself from the paradigm of "struggle" and developed a theory more concerned with the "normative reconstruction" of the institutions of our democratic life, Honneth would end up paying less attention to the relation with social research. We argue that Horkheimer's works of the decade of 1930 could indirectly help us to solve some methodological difficulties concerning a kind of "new sociological deficit" that critical theory would be facing today.
\end{abstract}

Keywords: critical theory; social research; Horkheimer; Honneth; recognition theory.

DOI: http://dx.doi.org/10.11606/issn.2318-9800.v22i2p63-76

Desde muito cedo, Axel Honneth se defrontou com a história da primeira geração da teoria crítica, em especial com a figura de Max Horkheimer. As dificuldades apontadas por Honneth em confronto com os trabalhos de Horkheimer tanto reforçaram uma determinada maneira de recepcionar a história da primeira geração da teoria crítica quanto, principalmente, marcaram decisivamente os obstáculos e desafios da renovação desta tradição de pensamento. Na esteira de Jürgen Habermas, Honneth adotou uma perspectiva crítica diante da obra deixada por Horkheimer. Porém, é preciso sublinhar, ele identificou também de que maneira poderíamos dar continuidade às contribuições originais de Horkheimer consideradas frutíferas para o

* Uma versão levemente modificada do presente texto foi apresentada no Colóquio Internacional Max Horkheimer e a Teoria Crítica, ocorrido em setembro de 2016, na USP. 
estado atual da teoria crítica.

Honneth compartilhou com Horkheimer a ideia geral de que a teoria crítica pode ser entendida como uma teoria social interdisciplinar com propósito prático. Esta formulação é propositalmente aberta para pensar um fio condutor entre as diferentes gerações desta tradição de pensamento, mas também esconde pressupostos muito exigentes para sabermos quem pode ainda hoje fazer parte dela com êxito. Ela basicamente nos diz que uma teoria crítica da sociedade bem-sucedida, por assim dizer, deveria fundar seu ponto de vista sobre as normas imanentes nas próprias relações sociais e encontrar seu elemento crítico na experiência social de sua época (Honneth, 1989, cap.1). Horkheimer foi uma figura central nesta formulação, e é dele que Honneth retira suas expectativas teóricas mais importantes: de um lado, a pretensão de elaborar uma teoria voltada às experiências pré-científicas e cuja capacidade crítica estaria inscrita nas próprias interações sociais; de outro lado, fundamentar uma teoria crítica da sociedade capaz de assumir a difícil tarefa de refletir sobre seu "contexto de surgimento", assim como suas possibilidades políticas de realização prática e emancipatória.

Todas as preocupações que giravam em torno das atividades ligadas ao Instituto de Pesquisa Social, do qual Horkheimer foi diretor desde cedo, formavam um mote comum para a renovação que Honneth pretendeu levar à cabo na qualidade de mais novo representante da teoria crítica. Em um texto publicado em 2000, intitulado “A dinâmica social do desrespeito", Honneth parece compreender explicitamente seu próprio empreendimento de um modo muito vinculado à formulação das análises sociais decorrentes dos trabalhos da primeira geração. Segundo ele, a teoria crítica da sociedade

decorre de uma certa forma de crítica normativa, mais precisamente de uma crítica capaz de indicar a instância pré-científica à qual seu próprio ponto de vista crítico está vinculado, dito de outro modo, um interesse empírico ou uma experiência moral possui algum ancoramento extrateórico (Honneth, 2000, p.88).

Além disso, Honneth reconhece que todas essas tarefas de renovação da teoria crítica só poderiam ser cumpridas dentro de um contexto interdisciplinar, mais precisamente, caso a filosofia social se vinculasse à perspectiva interdisciplinar das ciências sociais - vinculação pela qual Horkheimer havia sido um dos principais responsáveis (Horkheimer, 2009a). De início, portanto, a caracterização que Habermas havia feito a respeito dos trabalhos do jovem Horkheimer parece ter marcado em grande medida a leitura do próprio Honneth. Para Habermas, o jovem Horkheimer, aquele da década de 1930, “pretendia continuar a filosofia com outros meios, a saber, com os meios das ciências sociais" (Habermas, 2015, p.144). Ou seja, segundo Habermas, "para Horkheimer, tratava-se da superação da filosofia na teoria da sociedade; a transformação em ciências sociais fornecia ao pensamento filosófico 
a única chance de sobrevivência” (idem, p.145).

No entanto, se Honneth reconhece a importância de Horkheimer neste momento de elaboração de suas investigações filosóficas e das pesquisas sociais iniciais do Instituto, por outro lado, Honneth sublinha que a primeira geração foi incapaz de realizar suas próprias intenções de produzir uma teoria crítica sociologicamente orientada. Um dos principais intuitos de Honneth em sua obra, portanto, consiste em levar adiante a história de desenvolvimento da teoria crítica procurando com isto superar um certo déficit sociológico atribuído por ele mesmo aos autores desta tradição de pensamento que o precederam.

Não poderei analisar com profundidade neste texto em que medida a promessa honnethiana de dar primazia ao "social" de fato pôde ser cumprida em sua teoria do reconhecimento. Eu apenas gostaria de levantar uma hipótese segundo a qual uma volta às preocupações da pesquisa social de Horkheimer, consolidada em torno de um "materialismo interdisciplinar" e de uma "antropologia da sociedade burguesa", poderia contribuir para levar adiante o propósito de produzir um diagnóstico crítico fundado no "social". Estou supondo com isto que, de maneira talvez irônica, é a teoria de Honneth que acaba correndo o risco de padecer de um "déficit sociológico", e que muitas de suas próprias dificuldades poderiam ser sanadas se revisitássemos os trabalhos de Horkheimer da década de 1930.

Pretendo apresentar, primeiramente, a crítica de Honneth contra um suposto "funcionalismo marxista" que teria impregnado a primeira geração ligada ao Instituto de Pesquisa Social, levando então ao argumento central a respeito do "déficit sociológico". Trata-se aqui da tese sobre a incapacidade de Horkheimer realizar seu próprio programa, a saber, vincular filosofia social com uma análise da sociedade que também se baseasse em pesquisas sociais empíricas (I). Em seguida, sublinharei muito rapidamente a maneira com que Honneth renovou algumas preocupações de Horkheimer em sua própria teoria do reconhecimento, uma teoria fundada sobre experiências de desrespeito, indignação e formas de dominação social, de um lado, e sobre a motivação moral de lutas e conflitos sociais, de outro. Contudo, por ter se distanciado do paradigma da "luta" e desenvolvido uma teoria preocupada mais com a "reconstrução normativa" das instituições de nossa vida democrática, Honneth acabaria dando menos atenção à relação com a pesquisa social (II). Por fim, defendo de maneira apenas indicativa como os trabalhos de Horkheimer da década de 1930 poderiam indiretamente nos ajudar a resolver algumas dificuldades metodológicas concernentes a uma espécie de "novo déficit sociológico" que a teoria crítica estaria enfrentando hoje (III). 
De acordo com o argumento honnethiano em relação ao projeto de Horkheimer e às condições de realização no quadro de pesquisas levadas a cabo pelo Instituto - em especial na sua interpretação do texto "Teoria tradicional, teoria crítica", de 1937 -, a ideia original de teoria crítica teria sido apresentada segundo duas versões aparentemente complementares. 0 intuito de Honneth é mostrar que, quando confrontadas entre si, tais versões ressaltariam uma dificuldade crucial no projeto de Horkheimer, a saber, o da fundamentação adequada de uma análise social empiricamente orientada.

Na primeira versão, Horkheimer teria procurado esclarecer a gênese da ciência moderna. Seu intuito consistia em fazer com que a teoria tradicional reconhecesse o contexto constitutivo de sua própria atividade teórica. Para tanto, ela precisava ser pensada como práxis social em um processo social de produção. Apenas uma teoria autoconsciente de seu contexto de surgimento na qualidade de práxis produtiva poderia ser considerada crítica (Honneth, 1989, pp.13-14). No entanto, pergunta Honneth, como Horkheimer pode determinar com mais precisão conceitual a relação com o contexto prático a que a teoria está ligada de maneira constitutiva se desde o início ele reduz toda a práxis social ao processo de "trabalho social"? Afinal, toda atividade de produção da sociedade, seja reflexiva ou não em relação à sua própria atividade constitutiva, continua sendo uma práxis "produtiva". Em princípio, não haveria diferença entre uma atividade crítica e reflexiva e outra não-crítica, já que ambas seriam pensadas segundo o modelo do trabalho social concebido como ação instrumental (idem, p.17).

De acordo com Honneth, isso teria levado Horkheimer a formular uma segunda versão do conceito de teoria crítica. Assim, além da compreensão de seu próprio contexto de surgimento, a teoria crítica precisaria contar ainda com um tipo de comportamento crítico que permitisse, nas palavras de Honneth, "superar a ordem funcional estabelecida socialmente" (Honneth, 1989, p.20). Enquanto na esfera do trabalho social a espécie humana conserva e amplia sua vida social em proporção à conquista prática dos processos naturais, o "comportamento crítico" coloca em questão precisamente o modo existente de organização deste processo orientado à autoconservação social (idem, p.24) ${ }^{1}$. Ainda que ambas as versões sejam importantes

\footnotetext{
1 Em uma primeira passagem, Horkheimer afirma: "Mas existe também um comportamento humano que tem a própria sociedade como seu objeto. Ele não está voltado apenas a eliminar quaisquer males, pois estes lhe parecem antes ligados necessariamente a toda instituição da estrutural social. Ainda que este comportamento provenha da estrutura social, não é nem seu propósito consciente nem seu significado objetivo entendê-la a partir do que faz com que alguma coisa funcione melhor nesta estrutura. As categorias de melhor, útil, conveniente, produtivo, valioso, tais como são concebidas nessa ordem, são para ele suspeitas e não são de forma alguma premissas extracientíficas que dispensem sua atenção crítica" (Horkheimer, 2009b, pp.180-181). Um pouco depois, Horkheimer
} 
no argumento do texto de 1937, apenas a segunda versão (aquela que se preocuparia em investigar os sujeitos de "comportamento crítico" nas próprias esferas sociais) poderia remeter ao propósito emancipatório da teoria. Contudo, e este seria o problema central identificado no argumento honnethiano, Horkheimer não explica em que consiste "a estrutura específica da práxis social que ele mesmo define com o rótulo “comportamento crítico'” (idem, p.25).

Umas das tarefas principais aos olhos de Honneth consistiria então em desenvolver uma noção não-funcionalista de práxis social. Todo o programa original do "materialismo interdisciplinar" deveria estar voltado para esse problema. No entanto, Horkheimer não pôde esclarecer em termos conceituais o que entendia por uma práxis social reflexiva não somente porque teria negligenciado dimensões práticas da ação e da vida cotidianas, mas principalmente porque acabaria reencontrando em todos os ramos das pesquisas desenvolvidas pelo Instituto (na economia política, na psicanálise e na teoria da cultura) a mesma lógica de determinação imposta pela categoria do trabalho social. Por esta razão, Horkheimer não teria outra saída a não ser deixar de lado completamente a opção de uma possível "crítica da vida cotidiana" (Honneth, 1989, p.25), uma vez que seu reducionismo categorial o impediria que se compreendesse adequadamente outras dimensões existentes das práticas sociais.

Esses são os pontos centrais que sustentam o argumento de Honneth, permitindo-lhe sublinhar sua mais forte tese. As dificuldades apontadas demostrariam haver um déficit sociológico na ciência social interdisciplinar que Horkheimer compreendia como solução do programa de uma teoria crítica da sociedade, pois o marco programático e interdisciplinar da teoria crítica acabava por "derivar do trabalho toda a ação humana possível” (Honneth, 1989, p.38). Ainda que ao longo da década de 1930 o programa de um "materialismo interdisciplinar" estivesse voltado a construir uma análise social e encontrar, na dimensão das experiências cotidianas, os resquícios pré-científicos de uma atitude crítica, não foi casual que as pesquisas no âmbito do Instituto tivessem girado em torno da economia política. Por conseguinte, Horkheimer e outros membros do Instituto (que compuseram o círculo interno da primeira geração desta tradição de pensamento) realizaram a unidade teórica de seu programa porque mantiveram o "funcionalismo marxista" como pano de fundo para estabelecer uma dependência direta entre os diversos elementos das pesquisas empreendidas (Honneth, 1990). O primeiro resultado dessa unidade, em trabalhos coletivos como Autoridade e família, foi insuficiente, segundo a interpretação de Honneth, na medida em que "Horkheimer ocultou do domínio de objetos de uma ciência social interdisciplinar todo o espectro da ação social cotidiana” (Honneth, 1989, p.40).

se refere aos "sujeitos de comportamento crítico", os quais estão preocupados, sobretudo, com o caráter contraditório da sociedade existente (idem, p.181). 
As referências mais funcionalistas, que permaneceriam então presas aos efeitos reificantes do trabalho social, acabariam bloqueando a análise social voltada para dimensões da experiência cotidiana e para a dimensão cultural mais ampla. Isso acabaria inviabilizando diagnósticos do tempo em que potenciais emancipatórios (nos comportamentos críticos dos sujeitos) e formas sociais de dominação da subjetividade pudessem ser investigadas adequadamente. Se toda práxis social é categorialmente um tipo de atividade produtiva, os diagnósticos parecem já estar pré-determinados pela atividade do trabalho. O bloqueio da crítica se generaliza, já que não é passível de ser questionado por potenciais emancipatórios ou de resistência que deveriam ser investigados sempre de maneira imanente a seus contextos sociais de surgimento. Deste modo, fica enfraquecida no projeto interdisciplinar do Instituto tanto uma compreensão das diferentes formas de dominação social quanto das oposições e lutas que germinam de dentro das diversas esferas de sociabilidade.

Entre o modelo marxista de trabalho social e o modelo psicanalítico de socialização das pulsões individuais", afirma Honneth, "não existe um terceiro esquema teórico disponível que possa servir para desenvolver conceitualmente a estrutura última subjacente tanto à práxis cultural quanto ao conflito social(Honneth, 1989, p.38).

A primeira consequência atrelada à tese do déficit sociológico diz respeito a uma incoerência conceitual: Horkheimer faz desaparecer pouco a pouco todo conjunto de ações sociais cotidianas do âmbito de investigação de uma ciência social interdisciplinar (Honneth, 1989, p.40), já que, ao excluir toda forma de ação que não seja aquela da práxis produtiva, Horkheimer inviabilizou o universo da prática ordinária no qual sujeitos socializados desenvolvem suas atividades comuns, suas convicções morais e suas orientações normativas independentemente da lógica da produção. A segunda consequência afeta a organização disciplinar da teoria crítica: a sociologia passou a ter não um papel central, como seria de se esperar de uma teoria social interdisciplinar, mas sim uma posição marginal nesta organização.

Portanto, cada vez mais todo o "círculo interno" permaneceu ligado a um funcionalismo marxista que o levou a supor na realidade social uma esfera de dominação capitalista e de manipulação cultural que não permitia mais pensar uma margem para um tipo de “comportamento crítico" necessariamente almejado, entendido aqui como consciência pré-científica dos sujeitos com disposição para o conflito social. Assim, ao lado da quase impossibilidade de uma emancipação práticopolítica, diagnóstico que marcaria autores como Horkheimer e Theodor Adorno a partir de então, a teoria crítica legava para sua própria história de desenvolvimento a seguinte tarefa ainda não resolvida: ao se conservar o modelo de crítica derivado do trabalho social, é ainda preciso "criar um novo acesso teórico àquela esfera social em que um interesse na emancipação possa estar ancorado em termos précientíficos" (Honneth, 2000, p.92). 
II.

Honneth parte assim do déficit sociológico da teoria de Horkheimer para começar a reconstruir uma abordagem alternativa e própria, cujo objetivo é a reconstrução adequada do domínio do "social", e que será levada a cabo nos termos de sua teoria do reconhecimento. Segundo Honneth, o social se constitui sobre as relações de reconhecimento constituídas por meio de interações sociais intersubjetivas. Inicialmente, a tarefa da teoria crítica nos termos de Honneth consistiria assim em tentar reconstruir e explicitar as expectativas morais implícitas nas situações de conflito e em processo de luta por reconhecimento. Para que tais situações fossem apreendidas em um plano empírico, Honneth precisou mostrar como os padrões de reconhecimento estavam inscritos nas próprias práticas sociais (Honneth, 2003).

0 vínculo entre processos sociais e uma investigação interdisciplinar ainda estava mais presente no momento de elaboração de seu livro Luta por reconhecimento. Ciências sociais particulares, a sociologia da cultura e a antropologia cultural, o direito, a psicologia social e teorias dos movimentos sociais ainda eram mobilizadas para fundamentar em termos "materialistas", ou seja, do materialismo interdisciplinar, o conceito de reconhecimento e seus padrões. Neste livro, há uma preocupação com a análise de formas de desrespeito moral e de experiências de injustiça ligadas às abordagens de diferentes disciplinas sociais, cujo intuito explícito de Honneth consistia em superar quaisquer pressuposições "idealistas" ou "metafísicas". 0 "conceito de razão mundanizado" de Hegel precisaria dar lugar a uma "teoria social de teor normativo" (Honneth, 2003, p.118). Luta por reconhecimento dependia em seu projeto de uma reconstrução teórica sensível a comprovações históricas e sociológicas que fundamentariam adequadamente a tese segundo a qual formas de desrespeito social formam a fonte motivacional de confrontos sociais. Honneth não havia perdido de vista, portanto, o horizonte histórico-materialista que havia guiado as reflexões de Horkheimer, permitindo que a crítica teórica pudesse enraizar seu ponto de vista na realidade social.

Depois que a teoria da "luta por reconhecimento" se transformou em uma teoria do reconhecimento em geral, e o ponto de vista da experiência foi sendo substituído gradativamente pela preocupação com a "reconstrução normativa", o papel da filosofia tomou o primeiro plano. Exposições sobre o conceito normativamente mais adequado de liberdade, de justiça e de democracia puderam agora ser desenvolvidas independentemente de um cuidado com seus respectivos contextos de surgimento em processos sociais e, principalmente, na história das lutas sociais. Antes, a relação entre experiência e luta fez com que a teoria do reconhecimento fosse mais claramente compreendida como renovação dos "velhos problemas da teoria crítica", como ressalta Honneth, que consistiam em conjugar o projeto de um diagnóstico da 
atualidade orientado filosoficamente com uma análise social fundada sobre bases empíricas. Contudo, o distanciamento em relação ao paradigma da "luta" acabou sendo acompanhado também por um maior desacoplamento na obra de Honneth entre filosofia e pesquisa social. ${ }^{2}$

O que ocorreu então com a teoria do reconhecimento? Honneth, da abordagem ancorada no paradigma da luta por reconhecimento até suas mais atuais incursões a respeito da "reconstrução normativa" (Honneth, 2011) ${ }^{3}$ das instituições sociais de nossa eticidade democrática moderna, parece dar mais prioridade às questões normativas do que ao papel da pesquisa social. Em um artigo onde aborda a relação entre pesquisa social e o recente método reconstrutivo na teoria crítica, Olivier Voirol afirma de forma instrutiva:

de maneira geral, parece que os desenvolvimentos teóricos recentes dessa tradição intelectual acontecem sem grande consideração pela pesquisa social - nem pelos “testes" empíricos das ideias teóricas, tampouco pelo estímulo a novos projetos de pesquisa empírica no campo da Teoria Crítica (Voirol, 2012, p.82).

Essa atitude metodológica leva assim a uma consequência um tanto irônica na obra de Honneth, uma vez que seria então ele mesmo que passaria a correr o risco de padecer de um certo tipo de "déficit sociológico".

III.

A leitura crítica que Honneth apresentou de Horkheimer parece impedir uma interpretação dos trabalhos deste último que ajudariam a superar algumas dificuldades do estágio atual de sua própria teoria. Ao que me parece, justamente por reduzir parte importante das investigações de Horkheimer ao "funcionalismo marxista”, o próprio Honneth impossibilitou renovar uma vez mais suas inspirações teóricas nos trabalhos da década de 1930. Inspirações que, como mencionado, estavam atreladas à preocupação inicial de Honneth com uma crítica normativa ancorada em experiências morais pré-científicas ou extrateóricas. Pelo menos em um ponto isso me parece frutífero, a saber, no que diz respeito à articulação entre a fundamentação normativa da filosofia e uma pesquisa social interdisciplinar. Meu intuito central aqui consiste tão somente em corroborar a tentativa de retomar o vínculo entre filosofia social e pesquisa social presente na obra do Horkheimer da década de 1930, a qual poderia ajudar a superar algumas dificuldades da teoria crítica atual na versão reconstrutiva representada principalmente por Honneth. Mas terei de me limitar a alguns poucos apontamentos indicativos, sem desenvolver todas as implicações do meu próprio argumento.

2 Sobre como Honneth relacionou teoria e práxis com o conceito de reconhecimento e o gradativo distanciamento do paradigma da luta, cf. Melo (2014).

3 Para localizar o conceito de "reconstrução normativa" na obra de Honneth, ver Nobre (2013). 
No entanto, por outro lado, é importantíssimo para meu objetivo o fato de que esta visita ao Horkheimer da década de 1930 já vem sendo defendida com rigor por jovens pesquisadores da teoria crítica. Eu me apoio sobretudo nas tentativas já apresentadas em algumas ocasiões por John Abromeit (2011) e Olivier Voirol (2012, 2013). Pois eles nos ajudam a apontar, pelo menos de maneira indireta, dois complexos de problemas: a) pensar afinidades entre o interesse da teoria crítica atual em olhar para formas de dominação social e de experiências morais, de um lado, e os desafios dos textos de Horkheimer em relação às investigações sobre estruturas, sensibilidades e modos de vida cotidianos na Europa, de outro; b) pensar mais amplamente na relação entre o método reconstrutivo e sua relação com a pesquisa social. Isso nos permite redescobrir aspectos metodológicos ainda ricos e que se concentravam em um período importante das análises sociais desenvolvidas no Instituto com base no projeto interdisciplinar.

a. De um lado, a crítica honnethiana não leva tanto em consideração os esforços do próprio Horkheimer de evitar as armadilhas de uma abordagem mecanicista. Honneth diminui em muito os avanços empreendidos por Horkheimer principalmente no que concerne à pesquisa social empírica levada à cabo antes de 1937. Haveria talvez uma tendência a ler os trabalhos da década de 1930 à luz de Dialética do esclarecimento.

Mas existem afinidades temáticas claras entre a teoria crítica atual e aquela produzida pela primeira geração. Tanto a Horkheimer quanto a Honneth importa diagnosticar os aspectos psicológicos e culturais que explicam bloqueios ao “comportamento crítico" ou a superação prática das experiências de desrespeito e de sofrimento. Ou seja, também na primeira geração se buscou identificar, com a ajuda da psicologia e da psicanálise, os processos intrapsíquicos que contribuiriam para inibir as motivações da luta. É extremamente rica a análise feita por John Abromeit em seu livro sobre Horkheimer (Abromeit, 2011). Ele mostra como Horkheimer, desde Dämmerung até Autoridade e família e alguns escritos publicados logo após esta pesquisa coletiva [sobretudo, “Egoísmo e movimento de liberdade”], se preocupou com uma interpretação dos processos históricos que fosse também sensível aos momentos subjetivos. Seu livro acompanha em detalhes o modo com que Horkheimer havia explorado as formas em que o conhecimento, a percepção e as ações cotidianas se entrelaçavam constitutivamente (idem, p.219).

Esta preocupação de Horkheimer, que estou tentando destacar em defesa de sua atualidade, se deixa ver no programa esboçado em seu discurso inaugural como diretor do Instituto de Pesquisa Social, em 1931. Horkheimer sublinha a abrangência da análise interdisciplinar em relação a uma diversidade considerável de domínio de objetos. O programa do Instituto implica investigar

a questão acerca da conexão entre a vida econômica da sociedade, o desenvolvimento 
psíquico dos indivíduos e as transformações nas esferas culturais em sentido estrito, às quais não pertencem somente os assim chamados conteúdos espirituais da ciência, da religião, mas também o direito, os costumes, a moda, a opinião pública, o esporte, as formas de divertimento, o estilo de vida etc. (Horkheimer, 2009a, p.32).

Segundo Abromeit, cuja leitura contrasta com aquela de Honneth sobre o mesmo período 4 , o programa do "materialismo interdisciplinar" e, principalmente, o diagnóstico de uma "antropologia da época burguesa” contam com uma junção exitosa entre diferentes disciplinas, permitindo que uma análise rigorosa do capitalismo monopolista fosse conduzida em paralelo a investigações da psicologia e da cultura. De acordo com o próprio Abromeit, o modelo crítico do jovem Horkheimer seria extremamente frutífero, não só na sua própria época, mas também ainda hoje, porque se baseou em uma "teoria marxista da sociedade moderna como uma sociedade capitalista, movendo-se ao mesmo tempo para além do determinismo econômico e reconhecendo a 'autonomia relativa' da cultura e das estruturas psíquicas". (Abromeit, 2011, p.14).

Categorias psicanalíticas ajudariam, então, Horkheimer a oferecer explicações concretas sobre a razão de certos grupos de indivíduos agirem ideologicamente, muitas vezes contra o que aparentemente seriam seus próprios interesses. Problemas de comunicação distorcida entre os indivíduos foram analisados segundo disposições subjetivas, as quais, por sua vez, eram socialmente determinadas. $E$ as experiências concretas de vida que indivíduos partilhavam com outros membros, suas paixões e interesses, faziam assim parte da forma com que Horkheimer pretendeu decifrar os efeitos das estruturais sociais e das instituições culturais sobre o conhecimento, os sofrimentos e as ações dos sujeitos. (Abromeit, 2011, p.220). Haveria assim uma preocupação em mediar condições históricas com experiências subjetivas, mediação passível de ser analisada a partir de diferentes disciplinas de pesquisa e domínios de objetos.

Independente de um certo déficit democrático acertadamente apontado por Abromeit no que concerne aos trabalhos de Horkheimer da década de 1930, ao que me parece, estes textos e as pesquisas do Instituto ainda poderiam nos falar algo sobre como investigar os obstáculos ao desdobramento dos conflitos sociais em geral ou das lutas por reconhecimento, em particular.

b. O projeto das "ciências reconstrutivas", que remonta aos desenvolvimentos teóricos de Habermas na década de 1970 (Habermas, 2016), propunha se vincular

\footnotetext{
4 "A crítica de Honneth a Horkheimer se baseia em uma das objeções centrais de Habermas contra a teoria de Marx: que sua teoria da história e da sociedade estão baseadas em um modelo de trabalho concebido como ação instrumental, como a manipulação da natureza de acordo com imperativos racionais com respeito a fins, que obscurece o caráter fundamentalmente diferente da interação social mediada simbolicamente. Honneth essencialmente transpõe a objeção de Habermas a Marx contra Horkheimer, assumindo assim que este adotou completamente as hipóteses de Marx" (Abromeit, 2011, p.217).
} 
mais fortemente a um diálogo com a pesquisa social do que acabou ocorrendo na formulação de uma "reconstrução normativa” nos textos de Honneth. Pois neste caso, como Honneth ressaltou em algumas ocasiões, a filosofia social (independentemente da relação com o contexto de surgimento de suas categorias em um diagnóstico social empiricamente fundamentado) passou a não precisar mais se confrontar diretamente com a análise social propriamente dita. Isso acaba minando o propósito que nos parecia correto, e que animava a formulação inicial de Honneth, de que seria necessário manter um vínculo entre as construções teóricas e as práticas sociais efetivas. Pois seus trabalhos iniciais nos deram indicações da importância do lugar das ciências sociais, mas pouco fizeram nos últimos anos para mostrar como a teoria do reconhecimento e o método reconstrutivo poderiam responder ao problema da análise social. ${ }^{5}$

Assim, a volta às preocupações e atividades desenvolvidas por Horkheimer na década de 1930 poderia servir em grande medida para a teoria crítica produzida hoje (não apenas com Honneth, mas com autores e autoras como Rainer Forst, Nancy Fraser, Seyla Benhabib e Rahel Jaeggi). ${ }^{6}$ Isso porque seus trabalhos nos ajudam a orientar o fundamento normativo da crítica em direção a exigências sociológicas mais fortes, contribuindo ao final para a elaboração de um diagnóstico de tempo que leve em conta a normatividade imanente do social e de seus processos concretos.

Em outro trecho bastante representativo do projeto a ser desenvolvido no Instituto, Horkheimer afirma que seu programa implicava a partir de então

organizar, baseando-se nos problemas filosóficos atuais, (...) pesquisas em que deveriam participar filósofos, sociólogos, economistas, historiadores, psicólogos que, numa comunidade de trabalho duradoura, se unissem e fizessem em conjunto o que em outros campos um indivíduo pode fazer sozinho num laboratório e que todos os verdadeiros pesquisadores sempre têm feito: a saber, procurar acompanhar a amplitude de suas questões filosoficamente orientadas com a ajuda dos métodos científicos mais refinados, transformando-as e precisando-as ao longo do trabalho em torno do objeto, descobrindo novos métodos, sem , todavia, perder de vista o universal (Horkheimer, 2009a, pp.29-30).

Tal reacoplamento mais estreito com as ciências sociais certamente teria um impacto decisivo no estágio atual da teoria do reconhecimento, que na minha perspectiva ainda apresenta um potencial muito importante para a análise de patologias sociais e formas de conflito nas sociedades do presente. Isso se aplica diretamente à questão de saber qual tipo de conhecimento mais sociológico poderia contribuir para uma investigação da produção social de "gramáticas de luta", que, embora contem com pretensões normativas, devem continuar abertas à dinâmica e

\footnotetext{
5 Seria particularmente frutífera a via, não levada adiante, do emprego da noção de "paradoxo" como programa de pesquisa, categoria crítica e diagnóstico de tempo. Cf. Honneth e Hartmann (2010). Ver também os trabalhos reunidos em Honneth, Lindemann e Voswinkel (2013).

6 Acompanho aqui a interpretação sobre algumas dificuldades da teoria crítica atual de Nobre (2008).
} 
à complexidade de seus correspondentes contextos de surgimento. Neste caso, tanto a ideia de reconstrução normativa quanto a pretensão sistemática do conceito de reconhecimento deveriam ser compreendidas de maneira mais aberta. Este seria um desafio que se assemelha muito ao modo de fazer teoria crítica no jovem Horkheimer, para quem as categorias críticas empregadas tinham de ser constantemente revistas levando-se em consideração novos processos históricos empiricamente investigados pela pesquisa social (Horkheimer, 2009c).

O conceito de reconhecimento já vem sendo testado em diversas pesquisas empíricas (O’Neill e Smith, 2012). Seu sucesso se deve à capacidade de enriquecer diagnósticos críticos do presente e, em particular, a esclarecer processos de políticas de reconhecimento (como vemos, principalmente, em temas ligados a gênero, racismo e sexualidade, por exemplo). Mas também aprendemos com seus limites explicativos, ensinando-nos que o reconhecimento precisa ser repensado com análises sociais mais porosas a realidades históricas e espaciais em constante mudança. Portanto, todo o trabalho de reconstrução de perspectivas normativas enraizadas nos processos sociais e políticos analisados teria muito a se beneficiar da colaboração com pesquisas interdisciplinares, mesmo que isso implicasse custos às pretensões sistemáticas da teoria normativa defendida.

É preciso considerar também a complexidade do tema da pesquisa social para a teoria crítica. Existiriam diferentes maneiras de produzir diagnóstico, não conduzidas simplesmente por metodologias tradicionalmente empregadas e, muitas vezes, de viés positivista. Ela precisa ser aberta em relação à organização disciplinar, cruzar aspectos de uma investigação qualitativa com dados quantitativos, lançar mão de entrevistas e grupos focais, contar com observação participante e confrontar tentativas de diagnóstico de tempo. Mas sua vantagem é se servir da cultura, da política, da psicologia e da economia sem previamente determiná-las pela pretensão normativa da teoria.

Horkheimer contribuiria assim com novas formulações da teoria crítica, inclusive com a renovação dos diagnósticos do tempo presente. Diante desta enorme e necessária empreitada, penso especialmente em Honneth, caso assumíssemos hoje uma parte de seus desafios originais. Por esta razão, não se trata de uma contribuição direta, no sentido de utilizar sem mediações os resultados substantivos de seus trabalhos, mas no sentido de sempre procurarmos testar as categorias produzidas e os pontos de vista normativos inscritos na sociedade com uma cuidadosa análise social empiricamente orientada. Devemos continuar enfrentando as dificuldades dos representantes atuais da teoria crítica, mas também aprender com sua própria história de desenvolvimento das gerações que nos precederam - e penso que o jovem Horkheimer ainda serve de modelo frutífero para que possamos renovar, em sentido indireto, uma teoria social interdisciplinar com propósitos emancipatórios. 


\section{Referências}

Abromeit, J. (2011). Max Horkheimer and the Foundations of the Frankfurt School. Cambridge: Cambridge University Press.

Habermas, J. (2015). "Max Horkheimer: Sobre a história de desenvolvimento de sua obra”. In: Textos e contextos. São Paulo: UNESP.

UNESP.

- (2016). Para a reconstrução do materialismo histórico. São Paulo:

Honneth, A. (1989). Kritik der Macht. Frankfurt am Main: Suhrkamp.

- (1990). "Kritische Theorie. Vom Zentrum zur Peripherie einer Denktradition”. In: Honneth, A. Die zerrissene Welt des Sozialen. Frankfurt am Main: Suhrkamp.

. (2000). "Die Soziale Dynamik von MiBachtung: Zur Ortbestimmung einer kritischen Geselschaftstheorie”. In: Das Andere der Gerechtigkeit. Frankfurt am Main: Suhrkamp.

. (2003). Luta por reconhecimento: A gramática moral dos conflitos sociais. São Paulo: Editora 34.

Honneth, A. e Hartmann, M. (2010). “Paradoxien der kapitalistischen Modernisiserung. Eine Untersuchungsprogramm”. In: Honneth, A. Das Ich im Wir. Berlin: Suhrkamp.

Honneth, A., Lindemann, O. e Voswinkel, S. (2013). (orgs.). Strukturwandel der Anerkennung: Paradoxien sozialer Integration in der Gegenwart. Frankfurt am Main: Campus.

Horkheimer, M. (2009a). "Die gegenwärtige Lage der Sozialphilosophie und die Aufgaben eines Instituts für Sozialforschung”. In: Gesammelte Schriften. Bd. 3. Frankfurt am Main: Fischer.

(2009b). "Traditionelle und kritische Theorie". In: Gesammelte Schriften. Bd. 4. Frankfurt am Main: Fischer.

- (2009c). "Vorwort [zu Heft $1 / 2$ des I. Jahrgangs der Zeitschrift für Sozialforschung]”. In: Gesammelte Schriften. Bd. 3. Frankfurt am Main: Fischer.

Melo, R. (2014). Da teoria à práxis? Axel Honneth e as lutas por reconhecimento na teoria política contemporânea. Revista brasileira de ciência política, 15, pp.1736.

Nobre, M. (2013). "Reconstrução em dois níveis: Um aspecto do modelo crítico de Axel Honneth”. In: Melo, R. (org.). A teoria crítica de Axel Honneth: Reconhecimento, liberdade e crítica. São Paulo: Saraiva.

. (2008). "Teoria crítica hoje”. In: Melo, R., Repa, L., Keinert et al. (org.). Tensões e passagens: Filosofia crítica e modernidade. São Paulo: Esfera Pública.

O'Neill, S. e Smith, N. (org.). (2012). Recognition theory as social research: Investigating the dynamics of social conflict. New York: Palgrave Macmillan.

Voirol, Olivier. (2012). Teoria crítica e pesquisa social: Da dialética à reconstrução. Novos Estudos CEBRAP, 93, pp.81-99. 
Rúrion Melo

- (2013). "Filosofia social e pesquisa social: O 'problema hegeliano' de Max Horkheimer e Axel Honneth". In: Melo, R. (org.). A teoria crítica de Axel Honneth: Reconhecimento, liberdade e crítica. São Paulo: Saraiva.

Recebido em: 09.03.2017

Aceito em: 18.04.2017 